\title{
Measurement of the air-to-fuel ratio inside a passive pre-chamber of a fired spark-ignition engine
}

\author{
Nicolas Wippermann ${ }^{1} \mathbb{D} \cdot$ Olaf Thiele $^{2} \cdot$ Olaf Toedter $^{3} \cdot$ Thomas Koch $^{3}$
}

Received: 28 February 2020 / Accepted: 13 August 2020 / Published online: 27 August 2020

(c) The Author(s) 2020

\begin{abstract}
This paper investigates the local air-to-fuel ratio measurement within the pre-chamber of a spark-ignition engine by determining the absorption of light from hydrocarbons using an infrared sensor. The measurement was performed during fired and motored engine operation points and compared to the more common exhaust lambda measurements. The experiment provided data to compare the mixture preparation in a hot and cold environment of pre-chamber and main combustion chamber. The experiment also gives an indication regarding the possible use of a pre-chamber sensor in a motored engine at higher boost pressures and fuel mass flows, operation points that would overheat the sensor in a fired engine. The work also includes the analysis of the fuel delivery into the pre-chamber of a direct and indirect injection engine. Furthermore, pressure and temperature measurement within the pre-chamber provides information about the critical sensor environment and helps to understand the gas exchange between the two volumes.
\end{abstract}

Keywords Pre-chamber $\cdot$ Engine efficiency $\cdot$ Local lambda measurement $\cdot$ Jet ignition $\cdot$ Infrared lambda sensor

\begin{tabular}{ll}
\multicolumn{2}{l}{ Abbreviations } \\
AFR & Air-to-fuel ratio \\
CA & Crank angle \\
CAaTDCf & Crank angle after top dead center firing \\
COV & Coefficient of variation \\
IMEP & Indicated mean effective pressure \\
IR & Infrared \\
MCC & Main combustion chamber \\
MFB50 & 50\% Mass fraction burn point \\
OP & Operation point \\
SOI & Start of injection
\end{tabular}

Nicolas Wippermann

nicolas.wippermann@fr.renaultsportracing.com

Olaf Toedter

olaf.toedter@kit.edu

1 Renault Sport Racing, 1-15 Avenue du Président Kennedy, 91170 Viry-Châtillon, France

2 LaVision GmbH, Anna-Vandenhoeck-Ring 19, 37081 Goettingen, Germany

3 Institut für Kolbenmaschinen (IFKM), Karlsruher Institut für Technologie (KIT), Kaiserstraße 12, 76131 Karlsruhe, Germany

\section{Introduction}

The potential of pre-chamber ignition systems in modern combustion engines is evaluated in various publications $[3$, $5,21]$. Two of the main advantages of a passive pre-chamber combustion systems are the reduced burn duration and improved combustion stability.

During the development of a pre-chamber system, there is often focus on two main aspects beside the optimization of the combustion in the MCC. One is to establish a reliable system that supports the high engine load points without overheating [10]. The other is to assure the functionality of the ignition system at all engine OPs, for example cold start, partial load or heating of the catalytic converter. Passive prechambers, without an active fuel supply, have an advantage in cost and packaging as no additional fuel injector per cylinder is necessary. The main disadvantage is the limitation of an active control of the AFR in the pre-chamber. A common passive pre-chamber ignition system uses a spark ignition in a separate volume of approximately $2-3 \%$ of the combustion chamber volume at top dead center [2, 6, 12]. The combustion in the pre-chamber volume generates a rapid pressure increase and an ejection of hot gas jets into the main chamber. The main mixture is then ignited in parallel at multiple points around the chamber volume by those jets' temperature and radicals. Being without active enrichment, a passive 
pre-chamber is highly dependent on the amount of fuel that can be brought into the separate volume, as it represents the available energy at the start of combustion. To increase this fuel quantity that is ignited by the spark, different injection strategies have been developed in the past years [13].

Techniques to measure the fuel distribution in the combustion chamber often use ionization or IR sensors $[4,7,20]$. The measurement of the local lambda in the pre-chamber is a relevant parameter to evaluate and compare different injection systems and the resulting combustion. The measured data can also help validate CFD simulations that predict the lambda distribution within the pre-chamber. The computational fluid dynamics simulation of the AFR in the prechamber is a common development tool to compare different designs [22, 23].

The pressure measurement inside the pre-chamber is a further common technique in pre-chamber development $[9,17,19]$. The additional use of thermocouples [18] gives an indication about the combustion temperature, combustion development and stress of the components. The fuel mass $(m)$, measured indirectly via the absorption of the IR spectrum of the hydrocarbons in the pre-chamber during an engine cycle, gives additional valuable information about the energy in the pre-chamber. Together with the pressure $(p)$ and temperature $(T)$, the variables of the thermodynamic equation for the pre-chamber are known at the beginning of the combustion. Equation (1) shows the dependency of the parameters during the engine cycle:

$p \frac{\mathrm{d} V}{\mathrm{~d} \phi}+V \frac{\mathrm{d} p}{\mathrm{~d} \phi}=m R \frac{\mathrm{d} T}{\mathrm{~d} \phi}+m T \frac{\mathrm{d} R}{\mathrm{~d} \phi}+R T \frac{\mathrm{d} m}{\mathrm{~d} \phi}$.

The homogenous mixture preparation of an indirect injection leads to the same air-fuel mixture in pre-chamber and main combustion chamber. On the contrary, a direct injection with its inhomogeneous mixture preparation results in different AFRs for both volumes. To measure the impact of different injection timings and the difference between port and direct injection, a local lambda sensor is implemented in a passive pre-chamber.

\subsection{Pre-chamber spark plug}

The system used for the local lambda measurement is the LaVision Internal Combustion Optical Sensor (ICOS). The M5 sensor measures the absorption of infrared light between the ends of two fiber optic cables and a mirror in $4.8 \mathrm{~mm}$ distance. The absorbed light with a wavelength of about $3.4 \mu \mathrm{m}$ can then be related to the presence of hydrocarbons or $\mathrm{CO}_{2}$. This measurement has proven to be useful in the development of combustion engines [11, 14]. The evaluated parameter in this work is the measured fuel destiny in $\mathrm{mol} / \mathrm{m}^{3}$ which is proportional to the absorption of the hydrocarbons

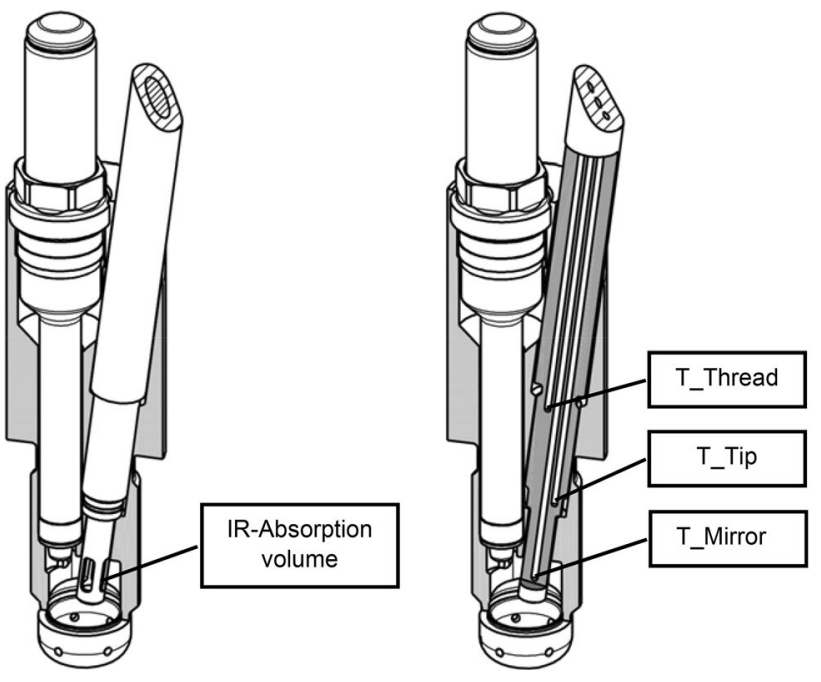

Fig. 1 M12 pre-chamber with the infrared M5 sensor on the left and three temperature measurement positions on the right side

Table 1 Measured sensor conditions in the pre-chamber compared to the authorized maximum values by LaVision [16]

\begin{tabular}{lll}
\hline Value & Measured & Authorized \\
\hline Temperature thread & $429 \mathrm{~K}$ & $470 \mathrm{~K}$ \\
Temperature tip & $470 \mathrm{~K}$ & $650 \mathrm{~K}$ \\
Temperature mirror & $590 \mathrm{~K}$ & - \\
IMEP & $9 \mathrm{bar}$ & $8 \mathrm{bar}$ \\
Max. cylinder pressure & $50 \mathrm{bar}$ & $200 \mathrm{bar}$ \\
\hline
\end{tabular}

between the mirror and the fiber optic cables. A calculation based on the quantity of air in the cylinder and the cylinder pressure compensation gives a local lambda value [15]. The sampling frequency of the system is $30 \mathrm{kHz}$, which equals $0.4^{\circ} \mathrm{CA}$ at $2000 \mathrm{rpm}$. In the experimental set up, the ICOS device is situated close to the spark gap in the pre-chamber volume as shown in the following picture:

Figure 1 shows the pre-chamber packaging with the M5 sensor. The spark plug on the left side shows the ICOS sensor position, on the right side of the three thermocouples. The M12 1.25 pre-chamber spark plug has six holes with a $0.8 \mathrm{~mm}$ diameter and a volume of $439 \mathrm{~mm}^{3}$ including the ICOS sensor measured in Catia V5. Before the lambda sensor is mounted into the pre-chamber, the pressure and critical temperatures within the pre-chamber are measured using Type $\mathrm{K}$ thermocouples. This ensures that the maximum authorized values for the sensor are not reached. The revealed temperatures are in the range of the acceptable temperatures for the sensor as seen in Table 1. The authorized IMEP depends on the temperature of the IR-sensor mirror. If the mirror temperature is too high, the measurement drifts. In extreme cases, the mirror carrier melts and causes 
pre-ignition. However, no drift was experienced during the experiment, even at higher IMEPs of 9 bar.

Measured pressures in the pre-chamber and in the MCC are shown in Fig. 2. Pressure measurements inside the prechamber help with the understanding of the gas flow directions between the two volumes. The measured pressure is also used to confirm the pressure compensation in the

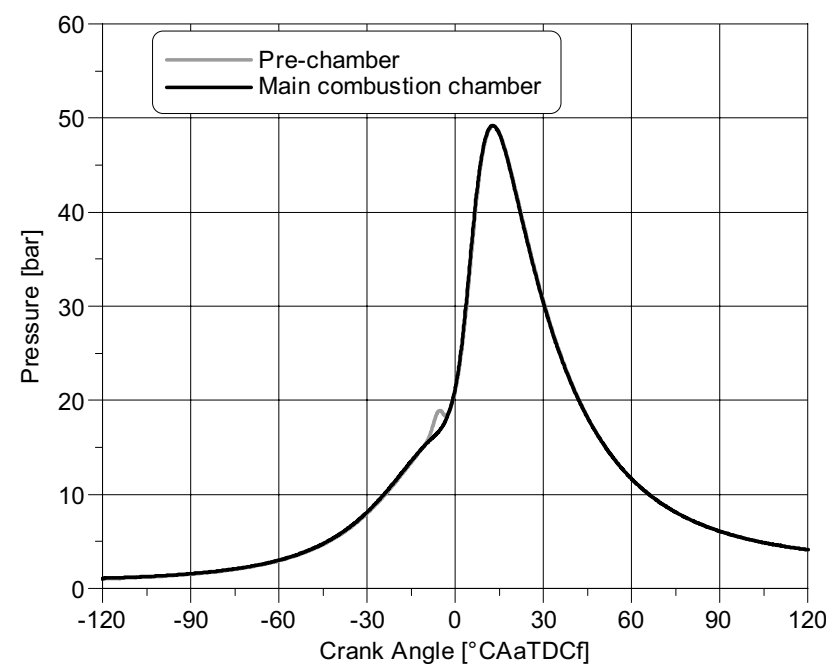

Fig. 2 Measured pressure signals in the pre-chamber and MCC at 8 bar IMEP and $2000 \mathrm{rpm}$

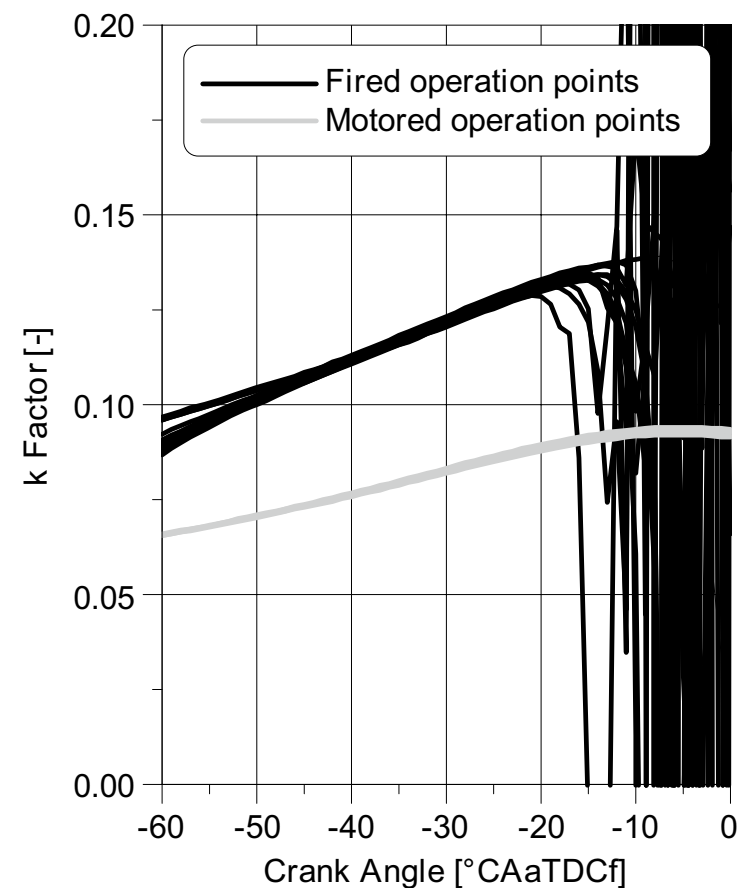

Fig. $3 k$ Factor for local lambda measurement in the pre-chamber for the fired and motored cycles in the experiment on the left side and the pressure correlation for the $k$ factor $0.126 \mathrm{bar} / \mathrm{K}$ at a cylinder tem- lambda calculation, as the pressure that is used in the LaVision software is measured in the MCC and not directly in the pre-chamber due to limited space.

Before ignition, the pressure difference between the prechamber and the combustion chamber in the area of interest is about $0.2 \mathrm{bar}$, with a sensor resolution of less than $0.1 \mathrm{bar}$, as shown in Fig. 6. The LaVision software determines the AFR with the measured fuel density $\left(\rho_{\mathrm{f}}\right)$ and a calculated air mass via the ideal gas law from the cylinder pressure $(p)$, the air temperature at inlet valve close $(T)$ and the volume of the combustion chamber. For the lambda value, the AFR is multiplied in the software by a factor, a possible offset is not used in the experiment [15]. The following Eq. (2) for the multiplier $(k)$ gives a connection between the measured values at the same crank angle.

$k$ Factor $=\frac{p}{\lambda * \rho_{\mathrm{f}} * T}$.

For an application of the IR sensor in a pre-chamber, the $k$ factor can be used to correct the lambda that is determined by the software, as the pressure that is seen by the sensor in the pre-chamber is lower due to the pressure drop via the pre-chamber orifices. The solution of Eq. (2) that is used in the experiments is shown in Fig. 3, the basis for the calculation is the crank angle resolved mean value of 200 cycles of each OP. The $\mathrm{k}$ factor changes for different

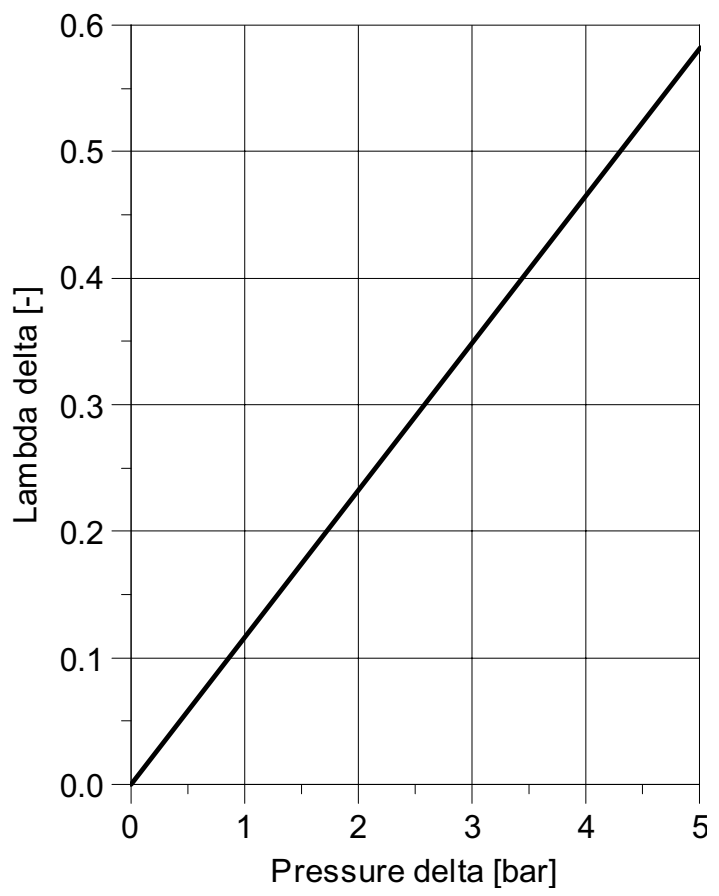

perature of $318 \mathrm{~K}$ at inlet valve close and a measured fuel density of 0.216 which corresponds to a 8 bar IMEP OP on the right side 
crank angles which are displayed in Fig. 3. Close to ignition at $-25^{\circ} \mathrm{CAaTDCf}$, its value is approximative 0.126 for the fired and 0.086 for the motored engine. The value for the motored engine differs due to its own calibration (Sect. 1.2).

The error for the lambda calculation at 0.2 bar difference between MCC and pre-chamber (Fig. 6) is less than 0.03 lambda points; therefore, no lambda correction is used in the experiment. However, for engines that have a greater pressure difference during the filling of the pre-chamber, this effect needs to be considered.

\subsection{Engine set up}

The experiments are performed in a test cell at the Institute of Internal Combustion Engines of the Karlsruhe Institute of Technology. A single cylinder engine with an external compressor for boost pressure adjustment is used. The displacement of the research engine corresponds with $498 \mathrm{cc}$ to the size of a standard passenger car. The technical specifications can be found in Table 2 .

The pre-chamber plug is mounted together with a Bosch HDEV5 Injector in parallel direction to the camshafts. The pre-chamber cap and the six-hole injector nozzle are in a central position between the four valves. The injector delivers fuel by a single injection per cycle. For the experiments with indirect injection, a HDEV5 injector is mounted on the intake side in front of a mixing volume, to ensure a homogenous mixture of air and fuel. The engine is equipped with different pressure sensors for the thermodynamic analysis. The pressure in the exhaust and the inlet of the cylinder head is measured with piezoresistive sensors (4045 and 4575 ) and the pressure in the pre-chamber and combustion chamber with a piezoelectric sensor (6054AR) from Kistler. For the recording of the data, a DEWETRON DEWE800 is used. The lambda value in the exhaust is measured with two lambda sensors (Bosch LSU4.9) and lambda meters (ETAS LA4).

Table 2 Specification of the used research single cylinder engine at the Institute of Internal Combustion Engines

\begin{tabular}{ll}
\hline Displaced volume & $498 \mathrm{cc}$ \\
Stroke & $90 \mathrm{~mm}$ \\
Bore & $84 \mathrm{~mm}$ \\
Compression ratio (without pre-chamber) & $10.5: 1$ \\
Number of valves & 4 \\
Inlet valve lobe center & $115^{\circ} \mathrm{CAaTDC}$ \\
Outlet valve lobe center & $-100^{\circ} \mathrm{CAaTDC}$ \\
Inlet/outlet valve lift & $8 \mathrm{~mm}$ \\
Injection system & Central mounted direct \\
& injection, indirect \\
& injection \\
Rail pressure & $200 \mathrm{bar}$ \\
\hline
\end{tabular}

\subsection{Engine operation}

The engine speed for the experiments is $2000 \mathrm{rpm}$. The pressure in the fuel rail for direct and indirect injection is fixed at 200 bar. Two load points with an IMEP of 4 bar and 8 bar are chosen for the comparison of the mixture in the prechamber. The inlet temperature is set to $313 \mathrm{~K}$. The MFB50 is held constant at $10^{\circ} \mathrm{CAaTDCf}$ by adjusting the ignition timing. The lambda variation is done by adapting the air in the cylinder for a constant injector opening duration. As the efficiency of the engine increases with higher AFRs, the IMEP also increases. During the experiments, this effect is not corrected as the focus was on the repeatable amount of fuel in the cylinder. The fuel that is used in the engine is RON95 E5.

The thermodynamic calculations are based on the pressure measurement in the MCC. No separate heat release rate was calculated for the pre-chamber.

The calibration of the IR sensor in the pre-chamber is done with the exhaust lambda sensor, at an OP with lambda 1 , a load of 4 bar IMEP and port injection. At this OP, the absorption of the light is correlated to a lambda value of 1 . The indirect injection assures the homogeneous mixture in the MCC and pre-chamber. The injector opening timing is adjusted for a stoichiometric AFR in the exhaust, the local sensor is then calibrated in the LaVision software using its calibration routine. The values for the sensor in the prechamber of this operating point are then used as reference for all fired cycles.

For the lambda measurement in the motored engine, the sensor must be recalibrated in the beginning. If the same calibration values would be used, the measured lambda in the pre-chamber will be constantly lower than in the hot engine. The lower lambda values are correlated with the higher amount of fuel in the pre-chamber. This is due to the lack of burned gas in the cylinder from the previous cycles and the backflow from the fueled gas from the exhaust during the opening of the exhaust valves.

\section{Results}

\subsection{Lambda variation for direct and indirect injection in a fired and motored engine}

The comparison between the different injector positions in a fired and motored engine gives an indication about the repeatability and the quantity of fuel that is brought into the pre-chamber. Together with the diverse air amounts of the AFR OPs, this results in different mixtures in the prechamber. The reference to this data is the lambda measurement in the exhaust system. 4 bar IMEP load points serve to compare the mixture preparation in the pre-chamber for 
lambda values from 0.9 to 1.2 . During this experiment, the injection timing for the direct injection is constant at $-300^{\circ} \mathrm{CAaTDCf}$. The inhomogeneous mixture of the direct injection can then be compared to the homogeneous mixture of the indirect injection. The lambda of each OP represents a mean value of 200 cycles at $-35^{\circ} \mathrm{CAaTDCf}$ (left graph in Fig. 4). This crank angle is chosen, because it is just before the earliest ignition timing (lambda 1.2 with direct injection) of all OPs, to assure the comparability between the individual points. After the ignition and the start of combustion, the measured fuel in the prechamber disappears. The measurement shows a delay of about $10^{\circ} \mathrm{CA}$ between the ignition in the pre-chamber and the disappearance of the fuel at the sensor position. During this time, the measured lambda in the pre-chamber is still decreasing rapidly. To see the evolution of the lambda in the pre-chamber, the right graph in Fig. 4 shows the values just before combustion at the sensor position in the prechamber at $-25^{\circ} \mathrm{CAaTDCf}$.

To estimate the stability of the amount of fuel that is delivered into the pre-chamber, the standard deviation of the measured lambda for each OP is calculated. A small deviation indicates a repeatable mixture preparation and as a result, steady combustion conditions in the pre-chamber volume. For the lambda measurement in the motored engine, the injection timing is held constant and the ignition is cut off. Figure 4 shows the lambda values for each OP together with its standard deviation.
Before the combustion at $-25^{\circ} \mathrm{CAaTDCf}$, the lambda values of the indirect injection are closer to the reference measurement than the ones of the direct injection. The fuel injection into the cylinder gives overall richer values with a maximal difference of 0.1 lambda points between the AFR in the pre-chamber and the exhaust measurement.

The standard deviation is lower for the motored OPs compared to the fired ones. However, the biggest dispersion for the lambda conditions can be observed between the direct and the indirect injection. The mixture preparation before the intake valves provides very repeatable lambda values in the pre-chamber. Less time for the mixture preparation of the direct injection and an inhomogeneous fuel concentration in the cylinder consequently, results in a greater variation of the lambda value in the pre-chamber. During the experiment, the local lambda measurement in the pre-chamber follows the trend of the exhaust measurement for both injector positions and the fired and motored engine.

\subsection{Crank angle resolved lambda for direct and indirect injection in a fired and motored engine}

The crank angle resolved lambda measurement during a cycle gives a deeper insight into the mixture preparation regarding the pre-chamber volume and is presented in Fig. 5. In addition to the lambda curves of the motored and fired engine, the heat release rates of the fired cycles
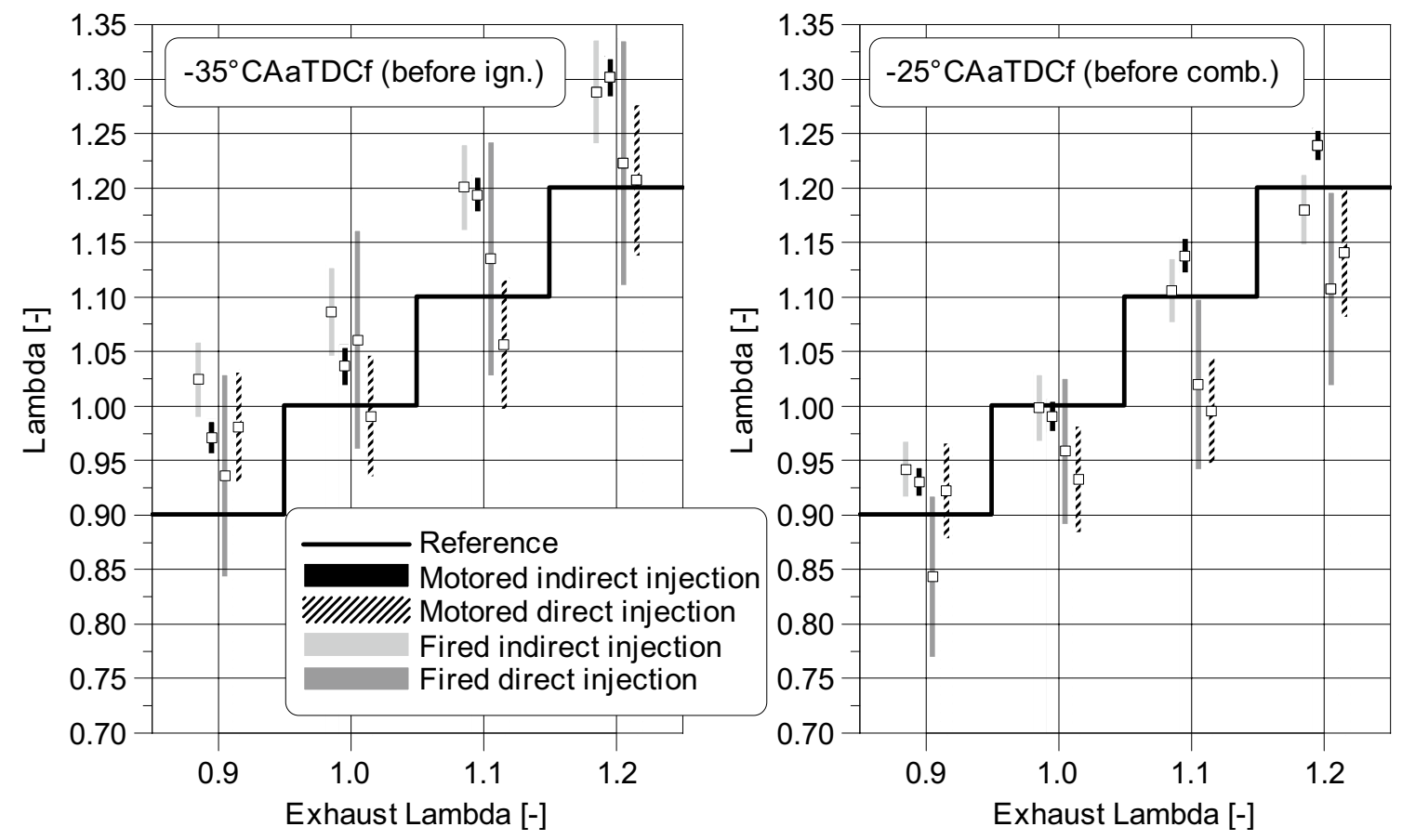

Fig. 4 Lambda comparison of the motored and fired engine with indirect and direct fuel injection at 4 bar IMEP. The left graph shows the values at $-35^{\circ} \mathrm{CAaTDCf}$ before earliest ignition and the right graph at $-25^{\circ} \mathrm{CAaTDCf}$ before earliest combustion begin in the pre-chamber 


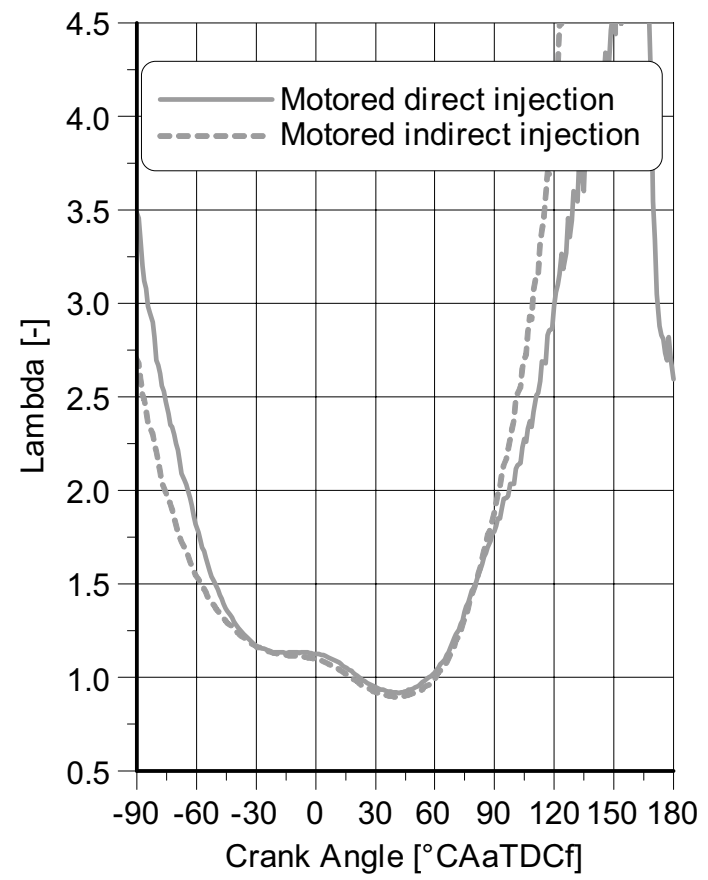

Fig. 5 Crank angle resolved lambda values in the pre-chamber for the motored and fired engine with indirect and direct injection. The center of the graph shows the heat release rate for direct and indirect

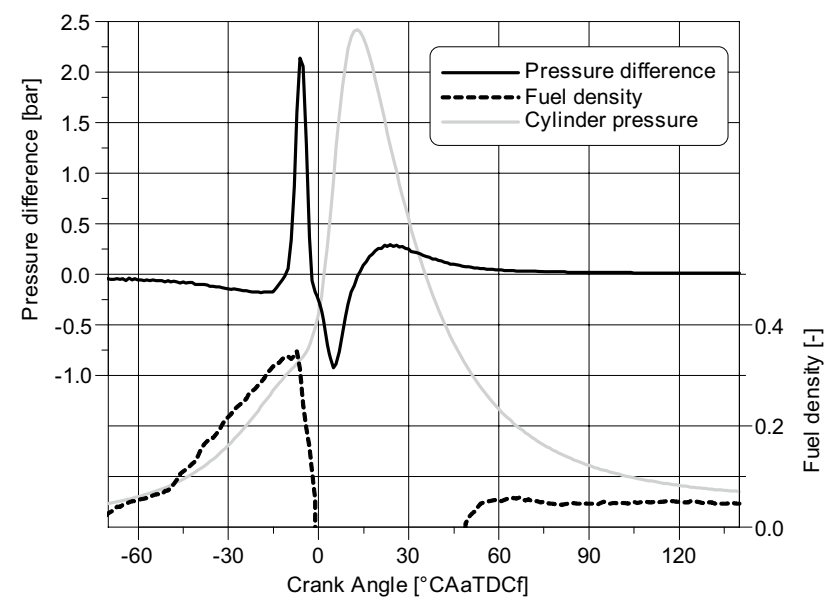

Fig. 6 Pressure difference between pre-chamber and MCC compared to the fuel density in the pre-chamber for the same operation point at lambda 1

are shown in the graph. All curves represent an average of 200 cycles, the injection timing for the direct injection is $300^{\circ} \mathrm{CAbTDCf}$. The reference exhaust lambda value for the OPs is 1.2. For the motored engine conditions, the injector opening duration is the same as for the equivalent fired operating point to inject the same fuel quantity. The ignition timing is $-33.5^{\circ} \mathrm{CAaTDCf}$ for the indirect injection and $-34^{\circ} \mathrm{CAaTDCf}$ for the direct injection to set the

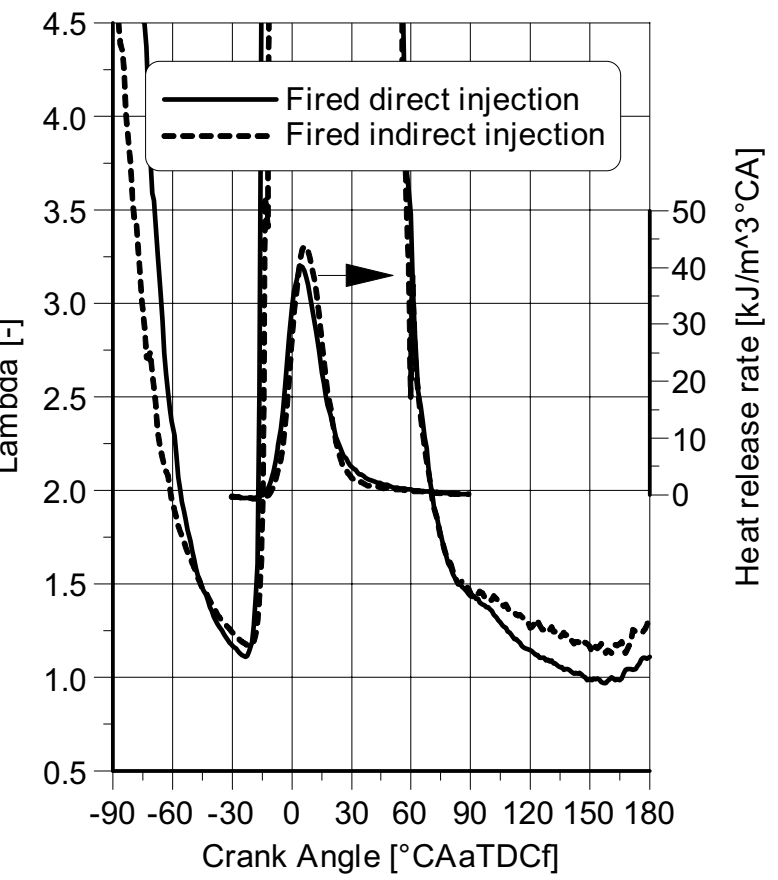

injection in the MCC at 4 bar IMEP, lambda 1.2 and $2000 \mathrm{rpm}$. During this time, no lambda is measured in the pre-chamber

MFB50 at $10^{\circ} \mathrm{CAaTDCf}$. The lambda that is measured by the sensor in the pre-chamber increases by approximately $10^{\circ} \mathrm{CA}$ later. During this time, the AFR still decreases to a lambda of 1.1 for the direct injection and 1.17 for the indirect injection.

In the compression phase, the sensor detects more fuel at earlier crank angle with the indirect injection. Due to the external mixture preparation, the amount of fuel in the cylinder is constant during compression. For the direct injection, the available time for the evaporation and mixture of fuel in air is limited to the time between the end of injection and the start of combustion. For an OP of 4 bar IMEP at lambda 1.2 , this means about $260^{\circ} \mathrm{CA}$ between end of injection and ignition. Figure 5 shows that the fuel during the direct injection reaches the sensor later, but the amount of fuel is higher in the pre-chamber at ignition.

Compared to the indirect injection, the applied ignition timing for the direct injection is earlier for the same MFB50. As well as the richer mixture in the pre-chamber, the combustion in the MCC is initiated earlier. This can be seen in Fig. 5, thus the lambda is increasing earlier in the pre-chamber. However, the combustion in the main chamber itself is faster with the homogenous mixture field of the indirect injection, as shown by the heat release rate. At the beginning of the combustion, the IR-sensor detection of fuel is reduced rapidly, the result is an increase of the lambda value in Fig. 5. After the combustion, the sensor is again measuring 
fuel in the pre-chamber at approximately $100^{\circ} \mathrm{CAaTDCf}$. This observation will be analyzed in Sect. 2.3.

The motored engine shows a similar behavior during the compression stroke with a later, faster and lower decrease of the lambda value. The absolute minimum of the lambda in the pre-chamber is observed at $40^{\circ} \mathrm{CAaTDCf}$ with a value of 0.9 for the direct injection.

\subsection{Gas exchange between pre-chamber and MCC}

The measurement of fuel in the pre-chamber after the combustion is unexpected. For the analysis of this behavior, the pressure difference between pre-chamber and MCC and the measured fuel density in the pre-chamber are compared. As the IR sensor replaces the pressure sensor in the prechamber, the data cannot be recorded during the same cycle. Figure 6 shows the mean curves of 200 cycles of the equal OPs with each measurement.

The graph represents also the rapid reduction of fuel after the ignition in the pre-chamber during the combustion at $5^{\circ} \mathrm{CAbTDCf}$. Fuel is then again present in the pre-chamber at $50^{\circ} \mathrm{CAaTDCf}$.

The differential pressure between both volumes helps to understand the scavenging of the pre-chamber. A negative pressure value represents a higher pressure in the MCC resulting in a mass flow into the pre-chamber. This occurs mainly during the compression phase before ignition. A positive pressure like the hot gas ejection between -10 and $-2.5^{\circ} \mathrm{CAaTDCf}$ results in a flow from the pre-chamber into the combustion chamber. The gas jets are then igniting the mixture in the MCC. During the following combustion in the $\mathrm{MCC}$, the pressure rise pushes gas into the pre-chamber from $-2.5^{\circ} \mathrm{CAaTDCf}$ to $15^{\circ} \mathrm{CAaTDCf}$. The $15^{\circ} \mathrm{CAaTDCf}$ corresponds to the angle with the maximum pressure in the combustion chamber. After this peak, gas is flowing back into the combustion chamber as the pressure in the MCC is decreasing. The measurement of fuel in the pre-chamber after $50^{\circ} \mathrm{CAaTDCf}$ means that the fluid flowing into the pre-chamber, during the pressure rise before the maximum cylinder pressure at $15^{\circ} \mathrm{CAaTDCf}$ is unburned gas.

\subsection{Variation of the start of injection for $\mathbf{4}$ bar IMEP}

The mixture preparation in the engine with direct injection is highly dependent on the injection timing. Figure 7 shows the lambda evolution in the pre-chamber during the compression stroke at the 4 bar IMEP OPs. The SOI is variated from $-360^{\circ}$ to $-240^{\circ} \mathrm{CAaTDCf}$, the graph shows the average value of 200 cycles. The ignition timing is set to have a constant MFB50 of $10^{\circ} \mathrm{CAaTDCf}$. An earlier start of injection does not always result in an earlier decrease of the lambda value in the pre-chamber. The earliest burnable lambda values are reached with an injection at $-290^{\circ}$ and

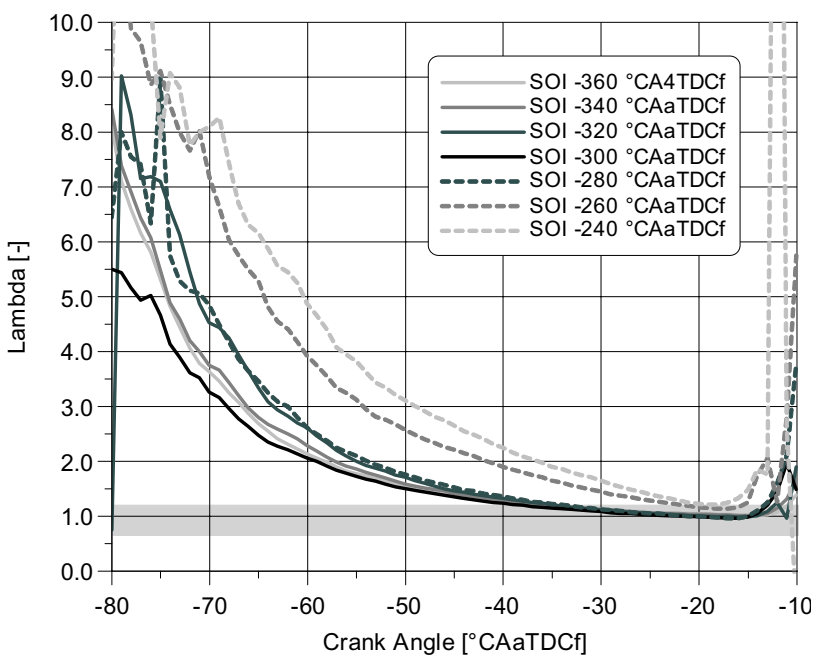

Fig. 7 Start of injection variation at 4 bar IMEP and a target lambda 1

$-300^{\circ} \mathrm{CAaTDCf}$. These injection timings are also delivering the highest amount of fuel into the pre-chamber. A SOI that is later than $-270^{\circ} \mathrm{CAaTDCf}$ results in a very late lambda decrease and a leaner mixture in the pre-chamber. The lambda curves for the other injection timings are closer together and reach equal lambda values before ignition.

Figure 7 shows the lambda decrease in crank angle resolution for seven injection timings. The gray box represents the normal operating range for a conventional gasoline engine from lambda 0.7 to 1.2 [8]. The fuel measurement confirms the best injection timing at $300^{\circ} \mathrm{CA}$ with the earliest mixture preparation and the richest AFR in the pre-chamber.

\subsection{Fuel delivery into the pre-chamber for different AFR and injection timings}

The comparison of the measured fuel density in the prechamber at different AFR shows a constant gradient for the OPs from lambda 0.9 to 1.2. As mentioned in Sect. 2.1, the injector opening time is held constantly during the AFR variation and the MFB50 is adjusted to $10^{\circ} \mathrm{CAaTDCf}$ by the ignition timing. The AFR is adjusted by the amount of air via the boost pressure. Figure 8 shows no direct impact on fuel delivery into the pre-chamber, from an increase of the air in the cylinder. However, the total amount of fuel in the pre-chamber is reduced for leaner conditions, as the ignition timing is earlier, due to a slower combustion. This can be seen in the left graph in Fig. 8 where the fuel density decreases after the start of combustion in the pre-chamber. The reached fuel density in the pre-chamber for lambda 1.2 is 0.155 , for lambda 0.9 , the value rises to 0.195 . The earlier combustion results in a pressure rise in the pre-chamber and an earlier ejection of jets into the MCC. Complementary to the AFR experiment, different SOIs do have an impact on 

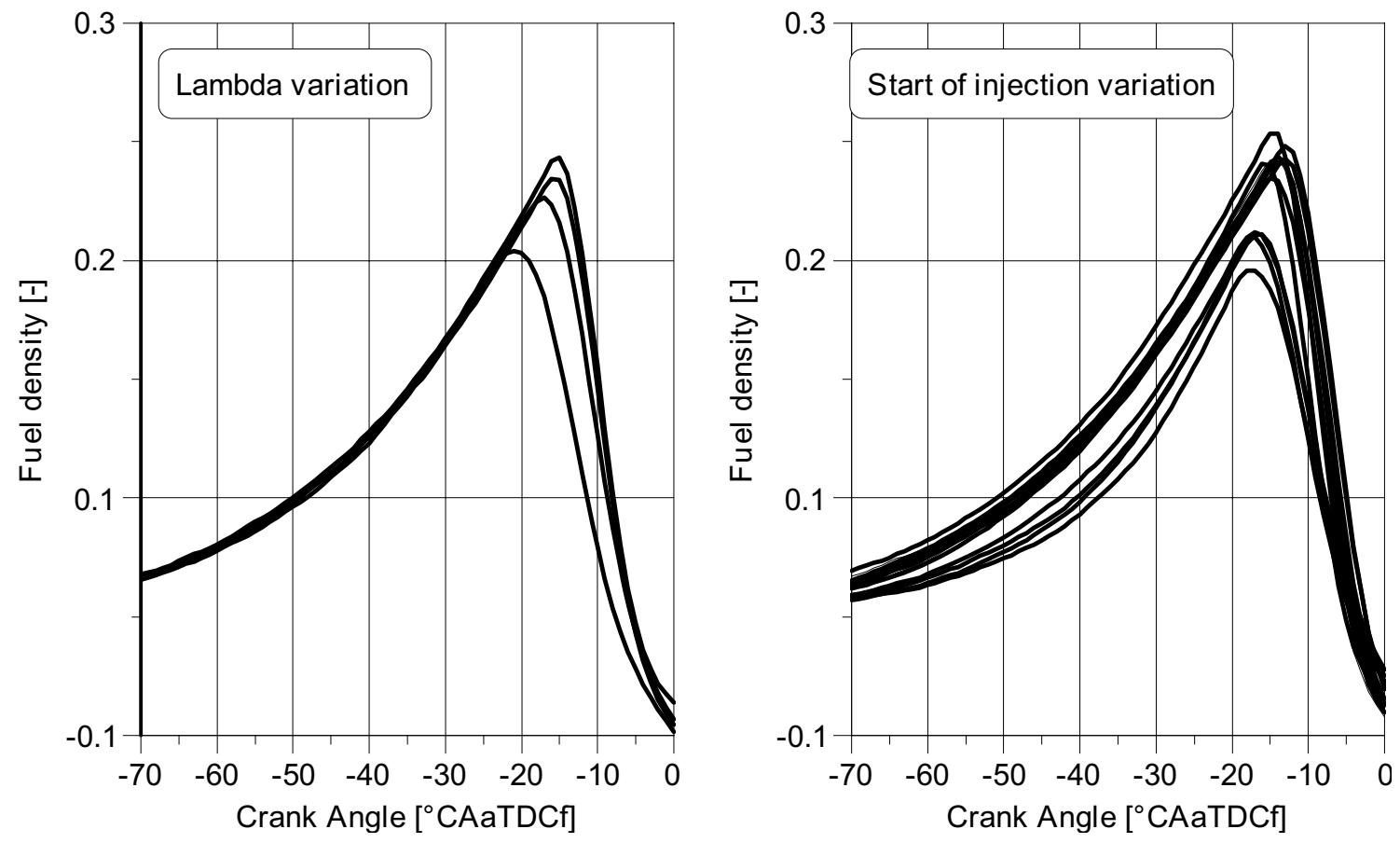

Fig. 8 Fuel density in the pre-chamber for different AFR in the left graph and different SOI in the right graph. The curves represent mean values of 200 cycles at 4 bar IMEP

the local lambda value in the pre-chamber, as described in Sect. 2.4. The gradient of the fuel density in the pre-chamber is displayed in the right graph of Fig. 8 .

\subsection{Lambda variation at 8 bar IMEP}

For further investigations, the load is mounted to an IMEP of 8 bar. The engine is operated with a direct fuel injection at $-300^{\circ} \mathrm{CAaTDCf}$. The lambda is varied by adjusting the air mass for a constant amount of fuel. The ignition timing is set to a MFB50 of $10^{\circ} \mathrm{CAaTDCf}$ for the OPs. The targeted lambda ranges from 0.9 to 1.3 and correlates with the exhaust gas measurement. A leaner mixture requires an earlier ignition timing due to its slower combustion, this can be seen in Fig. 9 by an earlier increase of the lambda, as the fuel in the pre-chamber is burned. The total fuel energy in the pre-chamber is reduced by this earlier ignition for the lean OPs. The measured fuel density gradient in the prechamber for the diverse AFR shows little difference, as in the OPs at 4 bar IMEP (Sect. 2.5). However, there is a tendency for a higher fuel delivery into the pre-chamber for leaner engine conditions at 8 bar IMEP. The maximum difference between the lambda in the pre-chamber and the exhaust is for the lean OP with a target value of 1.3. At this point, the lambda in the pre-chamber decreases to 1.22 . The potential impact on the lambda value due to the pressure drop between pre-chamber and MCC is discussed in displayed

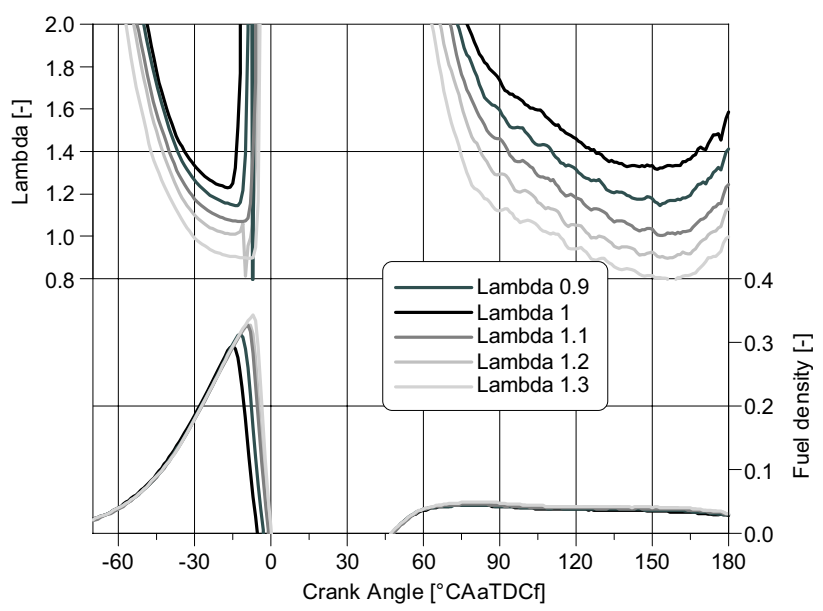

Fig. 9 Lambda measurement for different air-to-fuel ratios at 8 bar IMEP together with the fuel density in the pre-chamber

in Fig. 3. The phenomenon of the recirculated fuel into the pre-chamber volume after top dead center firing follows the air-fuel mixture.

\subsection{Variation of the start of injection for $\mathbf{8}$ bar IMEP}

To evaluate the impact on the combustion of different mixture preparations in the combustion chamber and in the pre-chamber, the SOI is variated from -240 to 


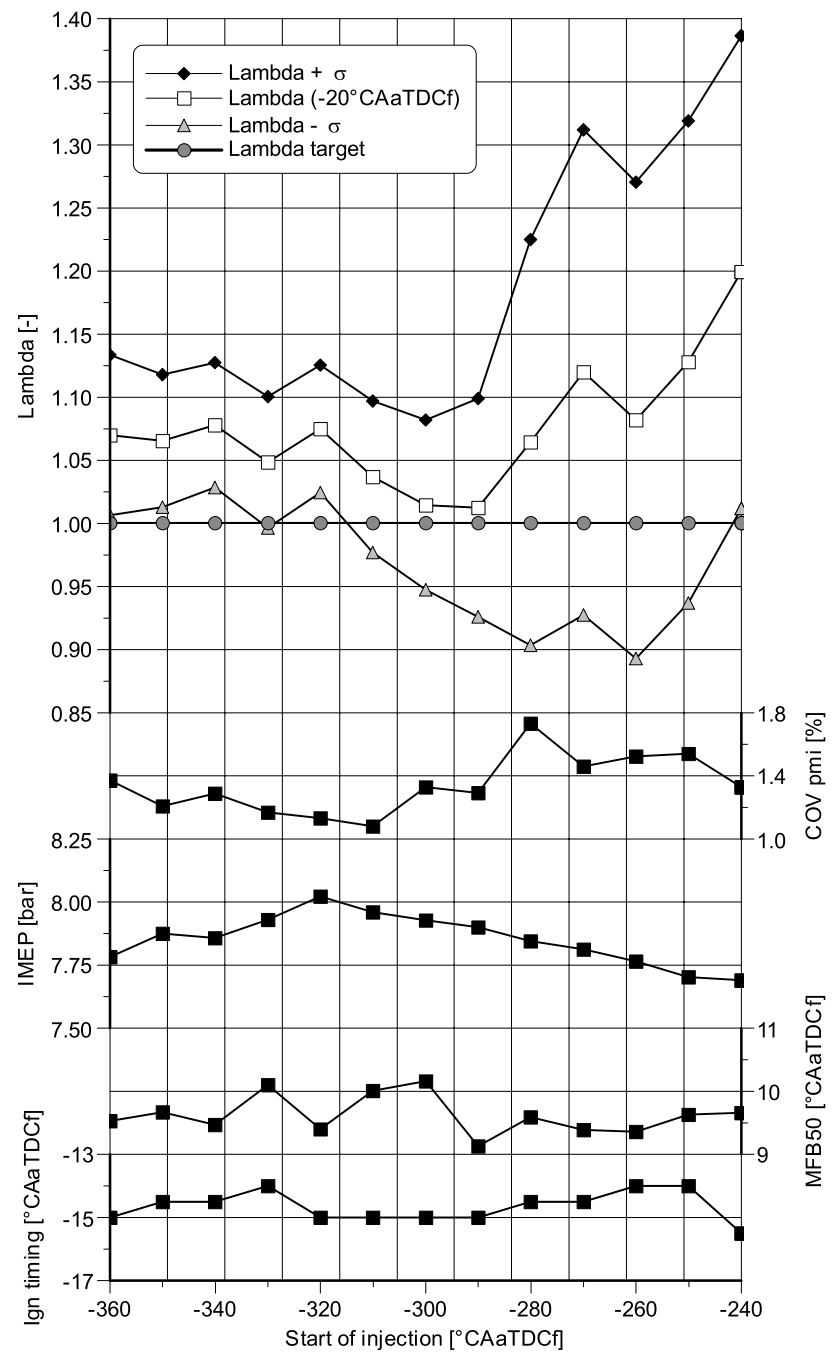

Fig. 10 Start of injection variation at target lambda 1 and 8 bar IMEP at $2000 \mathrm{rpm}$

- $360^{\circ} \mathrm{CAaTDCf}$. The MFB50 is set to $10^{\circ} \mathrm{CAaTDCf}$ by adjusting the ignition timing.

Figure 10 shows the mean value of 200 cycles of a combustion analysis together with the lambda measurement in the pre-chamber. The target value for the lambda in the exhaust is 1, the compared lambda in the pre-chamber is the measured value at $-20^{\circ} \mathrm{CAbTDCf}$. To visualize the fluctuation of the fuel in the pre-chamber, the standard deviation is added/subtracted to the mean value in Fig. 10. An injection from -290 to $-300^{\circ} \mathrm{CAaTDCf}$ results in the highest amount of fuel in the pre-chamber. An earlier injection has a small impact on the fluctuation around the targeted AFR. This behavior can be explained by the flat lambda curve in the MCC before ignition (Fig. 7 for the 4 bar IMEP OPs). Later injection timings increase the standard deviation of the measured lambda together with its mean value, as the lambda gradient is increasing before ignition. A connection between the lambda in the pre-chamber and the quality of the combustion in the main chamber can be drawn. With a higher standard deviation and less energy due to a leaner mixture in the pre-chamber for later SOIs, the combustion in the MCC also deteriorates. The engine has the best stability with a COV IMEP of $1.08 \%$ for an injection at $310^{\circ} \mathrm{CAbT}$ DCf. An earlier injection is not beneficial for the cyclic variations of the mean pressure, but a later injection decreases the stability significantly up to $1.78 \%$. The performance of the engine has its maximum at $320^{\circ} \mathrm{CAbTDCf}$ with an IMEP of 8 bar. The IMEP then decreases to 7.7 bar for later injections.

\section{Discussion}

Although the lambda in the pre-chamber follows the trend of the exhaust gas measurement, the experiment with the LaVision ICOS shows that depending on the injection and the global AFR, a significant difference between the exhaust and the local lambda in the pre-chamber can be measured. For the same amount of injected fuel, the local lambda in the pre-chamber is hardly impacted by the amount of air in the MCC, but mostly by the injector position and the SOI.

This work shows that the delivery of fuel into the prechamber can be consistently higher with an optimized injection timing for the central direct injection, compared to the homogeneous indirect injection (Fig. 4). The injection of fuel in the combustion chamber and the resulting richer mixture around the spark plug position can achieve an enrichment of the pre-chamber.

The timing for the direct injection has a direct impact on the fuel evaporation in the combustion chamber independent from the load of the engine. An earlier fuel injection leaves more time for a good mixture between air and fuel, resulting in a more constant fuel distribution in the combustion chamber. Consequently, the mixture in the prechamber shows reduced variation. In Fig. 10, this is shown by the smaller standard deviation for lambda at earlier injection timings. The same effect has an indirect injection with its mixture preparation that starts outside the combustion chamber before the inlet valves. If the mixture preparation is poor, the standard deviation of the lambda in the prechamber increases. This variance effects the combustion, as for different fuel amounts, different ignition timings are needed (Fig. 9), as flame development angle and combustion duration increase. However, for an OP with a constant ignition timing, these parameters result in different ejection timings of the hot gas into the main chamber. Along with the less homogeneous mixture preparation in the MCC, the combustion is less stable and the COV of the IMEP is increased (Fig. 10). 
For leaner AFRs and direct injection, the OPs at 8 bar IMEP show a small increase in the fuel density within the pre-chamber at the same CA (Fig. 9). The fuel density of the 4 bar IMEP at different AFR shows equal values at the same CA (Fig. 8). Based on those results, there is little impact on the gradient of fuel delivery at a fixed injection timing for different amounts of air in the MCC. However, the total amount of fuel in the pre-chamber is reduced in lean conditions, due to the earlier ignition and ejection. The refueling effect after combustion starts earlier for richer conditions. Two expected causes can be connected to the fact that the inflowing fuel is not burned in the pre-chamber. The first cause is quenching of the flame in the pre-chamber holes, while the mixture is flowing back into the pre-chamber. The other cause is the presence of unburned mixture in the center of the MCC, while the hot gas jets initiate the combustion further outside in the combustion chamber. Optical measurements show the presence of unburned fuel close to the wholes until the end of combustion [1].

The phenomenon of refueling the pre-chamber is important to identify pre-chamber efficiency losses, as the fuel in this volume does not contribute to the combustion during the cycle. This observation leads to the conclusion, that a larger pre-chamber volume has a negative effect due to a larger amount of fuel that is stocked inside after combustion. On the other hand, refueling also helps to have a beneficial AFR at the beginning of the next cycle. It is still to investigate if the oxygen, flowing back into the pre-chamber is sufficient for another combustion.

Compared to the fired conditions, the lambda measurement in the motored engine shows the earliest decrease before TDCf. The lowest lambda value for the cycles without ignition can be observed slightly after TDCf (Fig. 5). This offset might be explained by the inertia of the air movement in the pre-chamber, as the sensor position is in the center of the pre-chamber and inflowing gas into the pre-chamber is generating a circular movement of the air. This centrifugal flow pushes the fuel to the outside of the pre-chamber, the motion then collapses due to the backflow into the MCC. The comparison of a fired and motored engine gives an additional indication of the use of the local lambda sensor in a pre-chamber without combustion. Due to the different composition of the exchanged gas, the lambda values of a motored engine are lower than in a fired one.

Once the sensor is calibrated in the motored engine, the values in the pre-chamber are comparable, as shown in Fig. 4. This confirms the possible use of the sensor in an engine without combustion but with the fuel and air amount of a higher load point, that is usually not supported by the sensor. Especially, single cylinder engines with adjustable boost pressure by compressors can so demonstrate almost all full load engine OPs.

\section{Conclusion and outlook}

This work proves the possibility to measure the amount of fuel in a pre-chamber under real engine conditions. As the mixture preparation in the MCC depends on the wall temperatures, the measurement during a fired cycle provides valuable information about the fuel that is brought into the pre-chamber. The scavenging of the pre-chamber depends on the pressure difference between itself and the MCC. These conditions only occur during combustion with its cylinder pressure. The work reveals data about the gas exchange of a pre-chamber with both, pressure and temperature of the engine. The motored engine shows an earlier decrease of lambda in the pre-chamber compared to the hot combustion chamber. The peak value of the measured fuel in the motored engine is $30^{\circ} \mathrm{CAaTDCf}$. The fired engine shows a later but faster decrease of lambda with a greater fuel density in the pre-chamber for rich conditions, due to a later ignition timing for the same MFB50.

The experiments confirm the impact on the AFR in the pre-chamber by different injection strategies and the possibility of an enrichment in the pre-chamber. For the same target value in the exhaust, the direct injection results in lower lambda values before ignition in the pre-chamber than the indirect injection. The impact of the SOI on the amount of fuel that is transported into the pre-chamber by the direct injector has been confirmed and measured.

The presence of fuel in the pre-chamber after combustion is one of the most surprising developments during this work. The fuel density rises in the pre-chamber, due to a backflow from the MCC during combustion. Furthermore, the comparison between the data with and without combustion verifies the possible use of the IR-lambda sensor in a motored engine.

Further investigations will focus on the refueling effect of the pre-chamber and its potential use in mixtures with restricted inflammation. The described tool can be used on experiments with different pre-chamber geometries to evaluate an engine-related optimum with respect to the fuel injection strategy.

Funding Open Access funding provided by Projekt DEAL..

\section{Compliance with ethical standards}

Conflict of interest On behalf of all authors, the corresponding author states that there is no conflict of interest.

Open Access This article is licensed under a Creative Commons Attribution 4.0 International License, which permits use, sharing, adaptation, distribution and reproduction in any medium or format, as long as you give appropriate credit to the original author(s) and the source, provide a link to the Creative Commons licence, and indicate if changes 
were made. The images or other third party material in this article are included in the article's Creative Commons licence, unless indicated otherwise in a credit line to the material. If material is not included in the article's Creative Commons licence and your intended use is not permitted by statutory regulation or exceeds the permitted use, you will need to obtain permission directly from the copyright holder. To view a copy of this licence, visit http://creativecommons.org/licenses/by/4.0/.

\section{References}

1. Attard, W.P., Toulson, E., Huisjen, A., Chen, X., Zhu, G., Schock, H.: Spark ignition and pre-chamber turbulent jet ignition combustion visualization. SAE Int. (2012). https://doi. org/10.4271/2012-01-0823

2. Baumgartner, L.S., Karmann, S., Backes, F., Stadler, A., Wachtmeister, G.: Experimental investigation of orifice design effects on a methane fuelled prechamber gas engine for automotive applications. SAE Int. (2017). https://doi.org/10.4271/2017-24-0096

3. Benajes, J., Novella, R., Gomez-Soriano, J., Martinez-Hernandiz, P.J., Libert, C., Dabiri, M.: Performance of the passive pre-chamber ignition concept in a spark-ignition engine for passenger car applications. SIA Powertrain \& Electronics, Paris (2019)

4. Berg, T., Thiele, O., Seefeldt, S., Vanhaelst, R.: Bestimmung der innermotorischen Gemischbildung durch optisches Indizieren. MTZ Motortech Z 74, 472-477 (2013). https://doi.org/10.1007/ s35146-013-0140-4

5. Blankmeister, M., Alp, M., Shimizu, E.: Passive pre-chamber spark plug for future gasoline combustion systems with direct injection. Ignition systems for gasoline engines: 4th international conference, Berlin (2018)

6. Gussak, L.A., Karpov, V.P., Slutskii, V.G., Spasskii, A.I.: Burning rate and stability in forechamber flame ignition in an internalcombustion engine. In: Combustion, explosion and shock waves volume, vol 19, pp 628-630 (1983)

7. Helmetsberger, P.: Experimentelle Gemischbildungsuntersuchungen an einem Ottomotor mit vollvariablem Ventiltrieb Direkteinspritzung und Aufladung. Dissertation, Technische Universität Graz (2010)

8. Heywood, J.B.: Internal combustion engine fundamentals. McGraw-Hill Education, New York (1988)

9. Hüchtebrock, B., Geiger, J., Dhongde, A., Sankhla, H.: Development of a natural gas combustion system for high specific power. MTZ Worldw Wiesb Germany 76, 30-35 (2015). https://doi. org/10.1007/s38313-015-0043-5
10. Janas, P., Niessner, W.: Towards a Thermally Robust Automotive Pre-Chamber Spark Plug for Turbocharged Direct Injection Gasoline Engines. Ignition Systems for Gasoline Engines: 4th International Conference, Berlin (2018)

11. Kallmeyer, F.: Methoden zur Untersuchung der lokalen Gemischzusammensetzung im DI-Ottomotor. Dissertation, Universität Duisburg-Essen (2009)

12. Kammerstätter, S.: Verbrennungsablauf und Schadstoffbildung in Erdgas-Großmotoren mit Vorkammerzündung. Dissertation, Technische Universität München (2012)

13. Kettner, M.: Experimentelle und numerische Untersuchungen zur Optimierung der Entflammung von mageren Gemischen bei Ottomotoren mit Direkteinspritzung. Dissertation, Universität Karlsruhe (TH) (2006)

14. Koenig, M.H., Hall, M.J.: Cycle-resolved measurements of precombustion fuel concentration near the spark plug in a gasoline SI Engine. SAE Technical Paper (1998)

15. LaVision GmbH.: ICOS evaluation software: Product-Manual (2017)

16. LaVision GmbH.: ICOS M5Probe: Product Manual (2019)

17. Lüft, M., Eicheldinger, S., Nguyen, H.D., Dohrmann, S., Kuppa, K.: Mitteldruck $>30$ bar bei Gasmotoren. Abschlussbericht über das Vorhaben Nr. 1201, Bad Neuenahr (2018)

18. Prager, M.: Analytische Modellierung des Betriebsverhaltens eines Gasmotors mit neuem Gaszündstrahlverfahren für hohe Leistungsdichte. Dissertation, Technische Universität München (2009)

19. Redtenbacher, C.: Analyse und Optimierung von Vorkammerbrennverfahren für Großgasmotoren. Dissertation, Technische Universität Graz (2012)

20. Reinmann, R., Saitzkoff, A., Mauss, F.: Local air-fuel ratio measurements using the spark plug as an ionization sensor. SAE Tech. Pap. (1997). https://doi.org/10.4271/970856

21. Sens, M., Binder, E., Reinicke, P., Riess, M., Stappenbeck, T., Wöbke, M.: Pre-chamber ignition and promising complementary technologies. 27th Aachen Colloquium, Aachen, Germany (2018)

22. Syrovatka, Z., Takats, M., Vavra, J.: Analysis of scavenged prechamber for light duty truck gas engine. SAE Int. (2017). https:// doi.org/10.4271/2017-24-0095

23. Wohlgemuth, $\mathrm{S}$.: $\mathrm{CO}_{2}$-optimierter Antrieb eines Kleinfahrzeuges. Dissertation, Technische Universität München (2016)

Publisher's Note Springer Nature remains neutral with regard to jurisdictional claims in published maps and institutional affiliations. 